\title{
Lógica y divinidad en el estoicismo
}

Logic and God in Stoicism

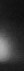

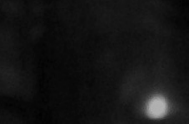

-
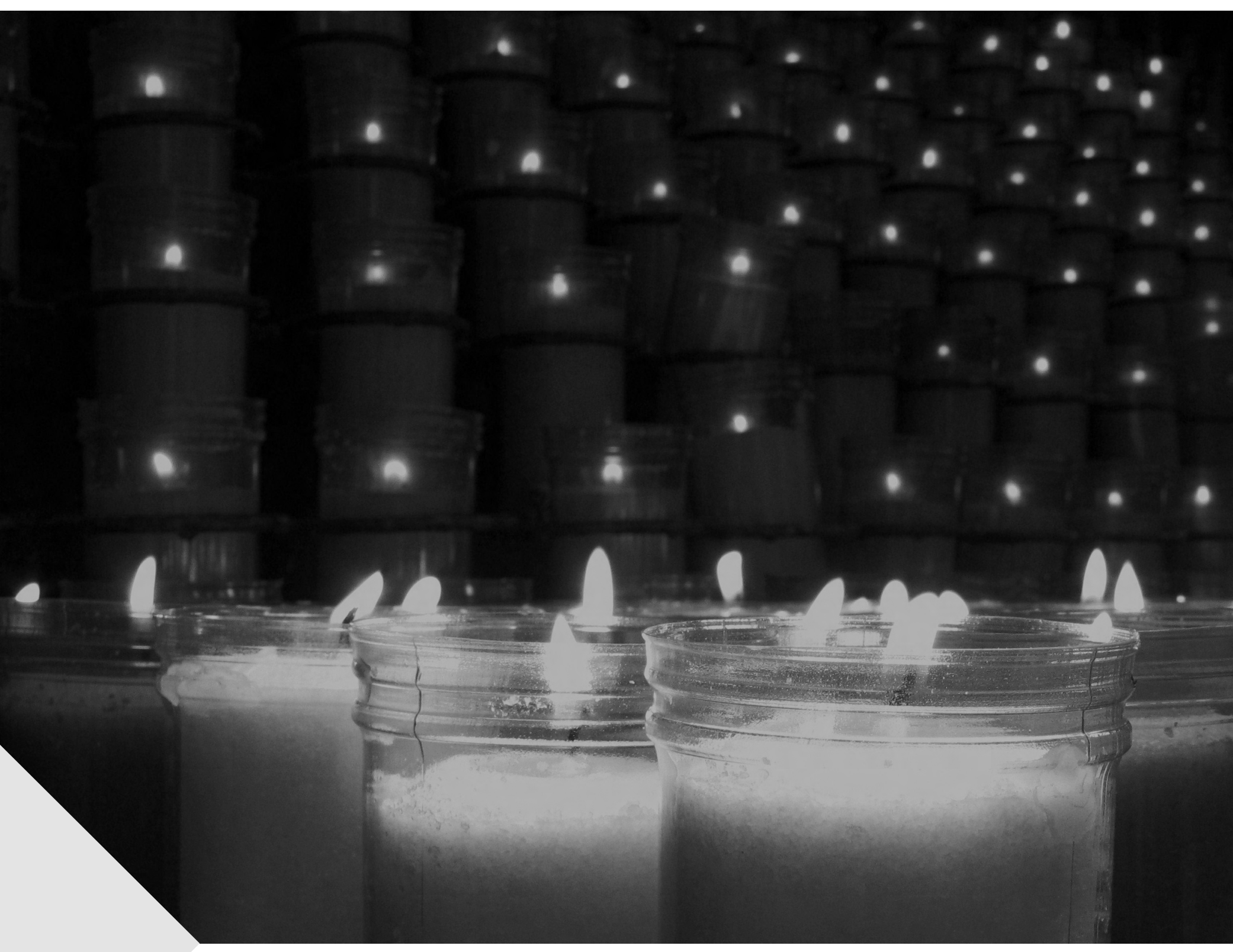


\title{
Lógica y divinidad en el estoicismo ${ }^{1}$
}

\section{Logic and God in Stoicism}

\author{
Óscar G. Flantrmsky Cárdenas² \\ Universitaria de Investigación y Desarrollo. Bucaramanga, Colombia
}

Artículo recibido en abril de 2016; artículo aceptado en junio de 2016

Citación del artículo: Flantrmsky, O. (2016). Lógica y divinidad en el estoicismo.

I+D Revista de Investigaciones, 8 (2), pp 83 - 90

\begin{abstract}
Resumen
El estoicismo es una de las escuelas filosóficas más conocidas de la antigüedad. Sin embargo, su estudio se ha visto reducido sólo a las cuestiones éticas y morales, desconociendo la complejidad de esta corriente filosófica. El presente artículo pretende mostrar cómo las diversas disciplinas que abarca no pueden estudiarse por separado, ya que constituyen un todo indisoluble. Por ello se pretende exponer la relación entre lógica y teología, bajo la premisa de que el estudio de la lógica es una forma de acercarse al conocimiento de la divinidad (logos), estudio que no puede desligarse de las demás disciplinas.
\end{abstract}

Palabra clave: Estoicismo, lógica, filosofía de la naturaleza, Dios. (Tesauro especializado en Filosofía, de la Universidad de Costa Rica).

\begin{abstract}
Stoicism is one of the most important schools of philosophy of the ancient Greece. Nevertheless its study has been reduced only for ethic and moral issues, and, for this reason, its complexity is not much known. This paper expounds how all disciplines that Stoicism includes cannot been studied separately, because they all are an indissoluble whole. Therefore the relation between logic and theology is expounded in this paper, under the premise that the study of logic is a method to approach to the knwoledge of God (logos), and that this study cannot be separated of the other disciplines.
\end{abstract}

Keywords: Stoicism, logic, Philosophy of nature, God (Thesaurus specializing in philosophy, University of Costa Rica).

\section{Introducción}

Tal vez una de las corrientes filosóficas que más se ha extendido en el tiempo sea el estoicismo. Muchos siglos después, autores como Kant o Spinoza aún conservaban ciertos puntos básicos de este pensamiento, aunque con notables diferencias. Inclusive, todavía hoy el término "estoico" es usado para referirse a alguien capaz de resistir la adversidad y ser moralmente consistente. Pero, ¿será esta denominación lo suficientemente completa como para abarcar el alcance de dicha doctrina? Si nos ceñimos a la concepción común, probablemente la res-

1. Artículo de reflexión, filosófica, enfocado en la línea antigua de filosofía.

2. Filósofo, Universidad Industrial de Santander. Abogado, Universidad Industrial de Santander. Máster en Filosofía y Estudios Clásicos, Universidad de Barcelona. Docente-Investigador del Grupo VIDOCQ. Universitaria de Investigación y Desarrollo, de la ciudad de Bucaramanga (Colombia). Dirección: Calle 9 23-55. PBX: 6352525. Correo electrónico institucional: oflatrmsky1@udi.edu.co 
puesta sólo quede circunscrita a lo moral y deje de lado el complejo sistema que implicaba el estoicismo, pues, de acuerdo con los testimonios brindados por filó sofos y doxógrafos, la moral no es sino una parte de toda su filosofía, que comprendía, además, lingüística, lógica, entre otros. Según Diógenes Laercio (1990), los estoicos:

"Comparan la filosofía con un animal, parangonando la lógica a los huesos y a los nervios, la ética a la carne y la física al alma. O también la comparan con un huevo: la lógica es la parte más externa, más dentro está la ética y la parte central corresponde a la física.O a un campo fértil, cuyo cerco es la lógica, la ética es el fruto y la física es la tierra o los árboles" (VII, 40)

Igual comparación es recogida por Sexto Empírico (1997):

"Dicen que una parte de la filosofía es la física, otra la ética y otra la lógica. - Lo dicen expresamente los del círculo de Jenócrates y los peripatéticos, e incluso los Estoicos adhieren precisamente a esta división. De aquí que persuasivamente comparen la filosofía con una tierra fértil y abundante en frutos, de modo que la parte elevada de los brotes la asemejan a la física, lo fértil de los frutos a la ética, y el cerco a la lógica. Otros dicen que es comparable a un huevo. En efecto, asemejan la yema, de la que algunos dicen que procede el polluelo, a la ética, la clara, que es el alimento de la yema, a la física; y la parte exterior, semejante a una ostra, a la lógica". (VII, 16)

De las anteriores referencias podemos apreciar su alcance doctrinal, que va más allá de la moral y se adentra en terrenos aparentemente disímiles, como la Lógica y la Física. Asimismo, las anteriores alusiones dan fe de una doctrina cuyos saberes que abarca unos saberes que están conectados entre sí. No en vano, Posidonio, como menciona más adelante Sexto (1997) en el fragmento citado, se opone a la comparación con el campo, ya que este símil lleva a pensar en partes separadas, algo que contraría lo que podríamos llamar "unidad de la filosofía", motivo por el cual propone que sea comparada con un ser vivo, en el que la física es la sangre y la carne, la lógica los huesos y los nervios, y la ética el alma. Igualmente, Diógenes Laercio (1990) reafirma el carácter unitario de su filosofía, cuando escribe que "ninguna parte de la filosofía, según el testimonio de algunos de ellos, es preferible a otras, sino que todas se mezclan" (VII, 40). Atendiendo a la información expuesta tanto por Sexto como Diógenes, no es posible, entonces, abordar el estudio de alguna de estas partes sin implicar a otra; no se puede estudiar ni la lógica ni la física sin tener en cuentas las implicaciones éticas, ni a su vez pretender estudiar la ética sin adentrarse en la física ni en la lógica. Es un todo conectado. Como bien señala Long: “El principal propósito de estas curiosas analogías es mostrar claramente cómo la filosofía es algo orgánico, al cual cada una de sus llamadas partes hace una contribución íntegra y necesaria" (Long, 1997, 122).

Por esta razón, la presente disertación tiene como objetivo concreto exponer la lógica estoica en relación con las consideraciones físicas y teológicas de su filosofía, y, más aún, a partir de esta perspectiva, validar su importancia como modo de acercamiento al conocimiento de la divinidad. Sin embargo, es necesario mencionar, en primer lugar, los puntos más eminentes de su física y su teología, para, posteriormente, conjugarlos con la lógica, de la que expondrán sus puntos esenciales, y así destacar el papel que ella desempeña. En ese sentido, el artículo se orienta a la reflexión suscitada a partir de la lectura de los fragmentos más destacados que dan fe del pensamiento de los primeros estoicos, o primera Stoa, con relación a sus puntos claves, ya mencionados anteriormente, para, mediante su análisis y exposición, establecer la relación entre teología y lógica, relación que usualmente tiende a omitirse, habida cuenta que el estudio tradicional del estoicismo se ha abordado básicamente desde la ética y aludiendo, mayormente, a los estoicos imperiales. De manera que el presente trabajo busca rescatar el pensamiento de los inicios de esta escuela en la relación, no siempre sencilla de establecer, entre la lógica y la divinidad, o, en otras palabras, entre razón y fe, objetivo al que se le puede añadir otra dificultad, como es el carácter fragmentario de los textos.

En efecto, el estudio de la primera Stoa tropieza con la casi nula supervivencia de textos que puedan atribuírsele directamente a sus representantes, lo que conlleva indagar en las noticias e información que, gracias a los no siempre fidedignos doxógrafos, apenas, por su naturale$\mathrm{za}$, son restringidas y sesgadas. Ante este problema, nunca ausente en la investigación sobre la filosofía antigua, también es preciso acudir a trabajos académicos realizados en diferentes momentos de la historia. Así pues, para el desarrollo del presente trabajo se han tomado los fragmentos doxográficos más relevantes sobre los primeros estoicos, así como trabajos académicos especializados en la temática propuesta, para reconstruir la visión lógico-teológica en los albores de esta Escuela.

\section{Mundo, física y divinidad en el estoicismo}

¿Existe una relación detectable entre la lógica y la teología en los inicios de la filosofía estoica? Si es así, ¿qué importancia tendría la lógica? Antes de responder, es 
preciso detenernos en algunos puntos básicos de esta doctrina. Así, el primer aspecto que debe destacarse de la filosofía estoica, ya que funge como una buena introducción, es la concepción de Universo. A partir de ésta es mucho más fácil comprender las demás. Digámoslo así, la concepción de Universo es el eje axial al que responden todas las otras ideas estoicas, como concatenadas con éste. $Y$ es precisamente como una concatenación como ha de entenderse la noción de Universo en los estoicos. Sin embargo, no está de más rescatar las palabras de Diógenes Laercio (1990), quien, al referirse a los estoicos y a su visión del universo, dice que ellos lo tienen como "divinidad única entre las sustancias, que posee la cualidad propia de ser indestructible y no engendrada: es el arquitecto del orden del mundo (...) es también el orden mismo de los astros y en tercer lugar, lo que está compuesto de ambos" (VIII, 137). Más concretamente, para los estoicos, el Universo, además de eterno, es un orden racional y por esta razón puede comprenderse desde una explicación de este tipo. Como lo manifiesta Brun, el universo "es un ser viviente, animado, razonable e inteligente" (Brun, 1977, 60).

¿Qué significa esto? La respuesta puede resultar bastante simple. Sin embargo, es la más adecuada. La razón, o $\lambda o ́ \gamma o c$, denominación estoica para la facultad atribuida al ser humano y por medio de la cual piensa, proyecta y habla $^{3}$, se halla incorporada totalmente en el Universo, creando una suerte de reciprocidad con el hombre, ya que éste, por ser parte de aquél, participa de este $\lambda o ́ \gamma o c$. Dicho de otra forma, "el hombre posee logos porque está inmerso, como pieza, en el Universo" (Long, 1997, 136). Esta concepción permite inferir que todo cuanto ocurra en él, en el Universo en tanto dotado de razón, como fenómenos naturales y actos humanos, responde a un orden del tipo causa-efecto y permite al hombre su posibilidad de conocimiento, al ser partícipe de este $\lambda$ óүoc.

Hasta este punto nos hemos referido a la noción de universo en el estoicismo. No obstante, esta noción no puede deslindarse de su concepción física, en cuanto no conciben universo y naturaleza como conceptos yuxtapuestos sino como denominaciones diferentes de un mismo concepto. Universo, dicen los estoicos, es todo lo que tiene cuerpo. La célebre expresión de Plutarco no

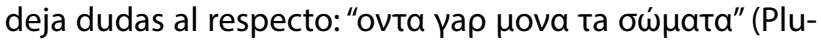
tarco, 1574, 646), que puede traducirse como "las cosas

3. Es preciso tener presente que "logos" y razón se encuentran en un nivel de sinonimia para los estoicos. Como se ha dicho, el logos es la facultad del discurso ordenado, orden que es dado por la razón. Etimológicamente, "logos" proviene del verbo griego $\lambda \dot{\gamma}$ $\varepsilon \mathrm{v}$, hablar con contenido racional y orden. Que el Universo tenga como propia esta facultad implica que, en la analogía con un discurso, todo cuanto ocurra en él está mediado por un orden preciso. que existen sólo son cuerpos". Para los estoicos, la naturaleza está conformada por cuerpos, y así también el universo, o mundo. La totalidad de todos los cuerpos conforma la Naturaleza, que a su vez es el universo, o mundo (el uso de tales términos es indiferente). Las cosas "incorpóreas" son subsistentes, mas no existen. Sintetizando con Brun, podemos decir que "el mundo sólo contiene cuerpos" (Brun, 1977, 28).

Ahora bien, si el mundo es corpóreo, ¿qué es dios? La respuesta más adecuada la brinda Rist (1995), al citar a Epicteto y el problema de dios, frente al cual concluye que es material, por cuanto existe. En ninguna de las fuentes que nos hablan del estoicismo se menciona que hayan negado a Dios; muy por el contrario, se recalca su visón teísta. En efecto, para los estoicos, Dios hace parte de las nociones comunes, es decir, las opiniones naturales que constituyen un sentido común a todos los hombres.

Según Cicerón (1999), Cleantes distinguió cuatro causas por las cuales los hombres se forman una noción de Dios: 1) El conocimiento previo de los acontecimientos futuros, pues la adivinación exige que haya dioses que no escondan sus designios; 2) Los bienes recibidos de la tierra, las buenas condiciones climáticas y otros tantos beneficios recibidos de la naturaleza, lo cual implica la existencia de alguien que los brinde; 3 ) Los fenómenos naturales que sobrecogen al hombre, de los cuales se puede extraer la idea de una fuerza que lo trasciende y doblega; y 4) El orden del mundo, el movimiento de los astros, los cuales muestran que todo implica una armonía rigurosa lejos del azar, así como también la existencia de alguien que controla y regula dichos movimientos.

En este orden de ideas, si los estoicos admiten la existencia de dios, significa que dios existe $y$, por tanto, es corpóreo. Mas no se trata de una materia aparte dentro del mundo. Dios, en el sentido estoico, es la naturaleza misma, o, si se quiere, es el mundo mismo, al que le es inherente el $\lambda$ óyoc. Dicho de otra manera, el $\lambda$ óyoc, el principio ordenador y explicativo de todo cuanto ocurre en el mundo, proviene de la divinidad puesto que ella es el mundo mismo. Que dios sea la naturaleza, puede leerse en Marco Aurelio: "Todo lo que es bueno para ti, oh Mundo, es bueno para mí. Nada es para mí ni prematuro ni tardío, si está maduro para ti. Todo lo que me traen las horas es para mí un fruto sabroso, oh Naturaleza. Todo viene de ti; tú estás en todo; todo vuelve a ti" (Marco A., 1998, IV, 23). De los versos anteriores, llama la atención que, en primer lugar, se invoca al mundo y luego a la Naturaleza, no obstante, se predica de ellos lo mismo, como si fuesen un mismo sujeto. $Y$ a decir verdad, lo son. Logos, Dios, Naturaleza, Fuego artesano (otra de sus denominaciones), todos son sinónimos, o, como lo expresa 
Long, "God, craftsman, artistic fire are alternative descriptions; providence, reason, law are aspects or properties of Nature" ${ }^{\prime 4}$ (Long, 1996, 137). Es decir, son lo mismo y cumplen la misma función: providencia, razón, ley, por la cual todo ocurre. ${ }^{5}$ Afirma Voelke (1973), que "pour le rationalisme stoïcien, la nature fait un avec le logos divin, omniprésent (...) Principe immanent au monde et à chacune de ses parties, (Voelke, 1973, 107)6 . Asimismo, del fragmento de Marco Aurelio, podemos extraer la fuerte presencia del $\lambda$ óyoc, como regidor de los acontecimientos, que tienen lugar cuando él lo dispone. Es decir, ordena, y ese orden constituye un sentido de la justicia en los estoicos. Esta conclusión también puede extraerse del

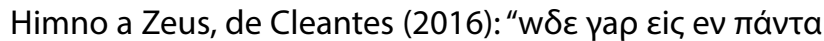

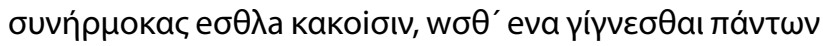

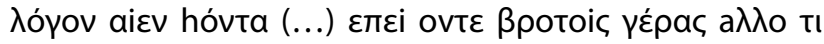

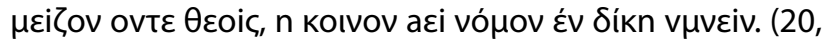
$35)^{7 " \prime}$

Sobre estos aspectos teológicos volveremos más adelante. Por ahora, a manera de conclusión, podemos afirmar que el mundo es la divinidad estoica: todo cuanto vemos que hay en él proviene de él mismo, y como tal, lo ordena, o, mejor, se ordena a sí mismo a partir de su razón o $\lambda$ óyoc. Al igual que concluye Brun (1977), la física estoica es una teología.

\section{La lógica y su relación con el mundo y dios}

Quizá la idea más relevante de la física estoica sea la relación causa-efecto con la que operan todas las cosas, y ello se debe a que la naturaleza responde al logos, razón inherente, y que a su vez, ella misma, es la divinidad. Todo cuanto ocurre en el mundo obedece a una causa, mas la causa no es incorpórea, pues si todo cuanto existe tiene cuerpo, las causas no son una excepción. Y es que la corporeidad se encuentra también en la lógica. Para

4. "Dios, artesano, fuego artífice son descripciones alternativas; providencia, razón, ley son aspectos o propiedades de la Naturaleza"

(La traducción es mía)

5. Esta pluralidad de nombres también es expresada por Cleantes al comienzo de su Himno a Zeus: "Bajo mil nombres siempre

omnipotente".

6. "Para el racionalismo estoico, la naturaleza se hace una con el logos divino, omnipresente (...) principio inmanente en el mundo y en cada una de sus partes" (La traducción es mía). Sin embargo, hay que tener en cuenta, como bien enfatiza Voelke, que no debemos olvidar que Dios carece de atributos humanos: "Mais n'oublions pas que leur Dieu est un principe d'ordre et d' harmonie qui, comme tel, ne revêt pas les attributs de la personalité" ("Mas no nos olvidemos que su Dios es un principio de orden y de armonía que, como tal, no es delos atributos

humanos") (Voelke, 1973, 112).

7. "Pues es así tal como en una sola cosa todas las cosas has armonizado,

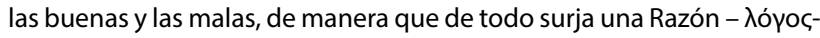
siempre existente (...) pues ni para los dioses ni para los hombres hay mayor privilegio que el celebrar por siempre y en justicia, con himnos, la ley universal". (La traducción es mía). los estoicos, si la lógica es la manera de expresar coherentemente lo que ocurre y emitir juicios acerca de esto, es necesario que lo expresado esté en concordancia con lo referido. $Y$ lo referido siempre es un existente, algo que tiene cuerpo, materia. El ejemplo más concreto son los $\lambda \varepsilon \kappa T o ́ v$ (o $\lambda \varepsilon \dot{\varepsilon} T a$, su plural), unidades que componen tanto el habla como las proposiciones estoicas. Los $\lambda \varepsilon ́$ kta, si bien son reconocidos como incorpóreos, no tienen existencia propia. Son subsistentes y refieren a un objeto concreto. Diógenes Laercio (1990) nos informa que los estoicos "sostienen que el $\lambda \varepsilon \kappa$ tóv es lo subsistente según una representación racional" (VII, 63). Una explicación más detallada la ofrece Sexto Empírico, citado por Kneale (1972):

"Los estoicos afirman que estos tres elementos se dan en conexión: aquello que es significado, aquello que lo significa y el objeto. De los tres elementos, aquello que significa corresponde al habla, como por ejemplo 'Dión'; aquello que es significado es lo que se revela mediante esta palabra y nosotros aprehendemos como subsistente gracias a nuestro pensamiento (...); el objeto, por último, es lo que existe físicamente fuera de nosotros, como por ejemplo el propio Dión (Kneale, 1972, 133).

De esta manera, el $\lambda \varepsilon \kappa$ Tóv está en concordancia con un objeto exterior y material. Este nexo entre $\lambda \varepsilon \kappa$ tóv y realidad tiene aún un sentido más amplio. Así como hemos visto que la naturaleza opera en el sentido causa efecto, esto es, que establece una relación entre las cosas existentes, así también ha de ser el $\lambda \varepsilon \kappa$ Tóv. Es decir, un $\lambda \varepsilon \kappa$ Tóv nos transmite la idea de un objeto externo, pero los objetos externos, por virtud del logos, se encuentra en relación con otros objetos. Es por esto que un solo $\lambda \varepsilon \kappa$ Tóv nos da una idea incompleta. Por ejemplo, si decimos "escribe", queremos saber "¿Quién?". O si decimos “Dión", queremos saber qué hace. Estos $\lambda \varepsilon ́$ kta son los llamados "deficientes", que Mates (1985) acierta en definir como enunciados incompletos. Recuérdese que debe existir una correlación con algo externo, y precisamente, frente a las cosas, los estoicos establecieron las categorías y por medio de ellas explicaban la naturaleza de las cosas. Rápidamente, podemos exponer las categorías así: 1) Substancia; 2) Cualidad; 3) Disposición; 4) Disposición relativa. Esta clasificación nos da la información acerca de un objeto, qué y cómo es, así como su función en el mundo y su relación con otros objetos. Siendo así como consideran que están las cosas en el mundo, en igual sentido debe reflejarse en el aspecto lógico-verbal. Es menester que existan lekta unidos entre sí. Ésta unión da origen a la proposición. La proposición, así, es un reflejo de un objeto.

Mates define las proposiciones como un $\lambda \varepsilon \kappa$ Tóv comple- 
to que es asertórico, o sea, verdadero o falso. La pregunta que emerge es: ¿Cómo afirmar la verdad o falsedad de una proposición? Esto es lo que se conoce como el "criterio de verdad". Sexto Empírico lo explica así: "Significa el objeto a la vista del que afirmamos que tales cosas existen y tales otras no, y que las primeras son verdaderas y las segundas son falsas" (Sexto Empírico, 1997, VII, 29). Esta explicación reafirma la idea de correlación de la proposición con la realidad, pero al mismo tiempo nos sitúa en un nuevo problema: el problema del conocimiento. No es preciso entrar en detalle en lo que atañe a este problema. Nos basta con destacar que las proposiciones han de coincidir con las representaciones que nos dan los objetos, y a partir de ello, afirmar la verdad o falsedad de aquellas, de suerte que también se presenta el problema de la verdad o falsedad de la representación, cuya respuesta, como apunta Rist, sigue siendo bastante difusa dada la falta de evidencias, por lo cual "en el estoicismo tenemos normalmente que suponer que las representaciones están de alguna forma conectadas a cosas verdaderas (es decir, existentes)" (Rist, 1995, 159).

La explicación anterior pone de manifiesto una particularidad de la lógica estoica y es su estrecha relación con la teoría del conocimiento. Dicho en otras palabras, la lógica parte del conocimiento que se tenga del mundo y su veracidad, aspecto que nos remite a la "dialéctica estoica", que es definida por Long (1997) como "conocimiento de lo que es verdadero, falso o ni verdadero ni falso (...). Las palabras, las cosas y las relaciones que unas y otras mantienen entre sí - tal es, en resumen, la materia de la dialéctica estoica" (Long, 1997, 125). Así pues, la lógica encierra teoría del conocimiento y dialéctica, ramificaciones que guardan relación con el mundo real. Esto también se recalca, dentro de la lógica, en la ausencia de proposiciones universales. En efecto, así como en el mundo no hay dos cosas iguales (cada cosa es una, con sus cualidades y sus relaciones), así tampoco en la lógica hay lugar a enunciados del tipo "todo hombre es mortal", por ejemplo. Para los estoicos, sólo existen los individuos, ya que el concepto universal es una palabra vacía. Dice Simplicio, citado por Brun (1977): "sostienen que lo general no es nada.

En efecto, el hombre no es nadie, porque la generalidad no es cosa alguna" (Brun, 1977, 25). Esto significa que en el mundo, lo que apreciamos son hombres, uno y otro, pero no apreciamos nunca el Hombre, ése que sea todos los hombres.

Y así como no existen las afirmaciones universales, tampoco es preocupación de la lógica estoica el estudio de los conceptos; si su visión de la lógica se encuentra en estrecha relación con el mundo mismo, ella no puede desligarse de él, y tal como conciben el mundo, como un orden causa-efecto, merced del logos, y en el que cada cosa es material y única, así también plantean sus proposiciones.

En efecto, las proposiciones estoicas, base de su lógica, están dadas en el ámbito de las implicaciones entre acontecimientos. Es decir, expresan la relación entre un antecedente y un consecuente. Los ejemplos clásicos de las proposiciones estoicas son recogidos por Brun (1977), los cuales son: "Si es día, hay luz", o "Si esta mujer tiene leche, entonces ha dado a luz". Incluso los razonamientos expresan una implicación entre acontecimientos y no una relación entre conceptos, lo que es entendible si su pretensión es no desligarse del mundo, mundo regido por la ley del logos, la causa y el efecto, la relación entre las cosas. Inclusive, al ahondar en los razonamientos y su clasificación, seguimos encontrando dicha característica.

Brun (1977), Mates (1985), Kneale (1972) y Vivieux-Reymond (1945) afirman que los razonamientos eran del tipo: Si es de día, hay luz; ahora bien, es de día; por lo tanto, hay luz. Estos se dividían en no concluyentes (aquellos en los cuales lo contrario de las proposiciones finales no se opone a las premisas. Por ejemplo: Si es de día, hay luz; ahora bien, es de día; por lo tanto, Dion se pasea) y concluyentes (que conducen a una conclusión de manera específica. Por ejemplo: Es falso que sea al mismo tiempo de día y de noche; ahora bien, es de día; por lo tanto, no es de noche). Dentro de estos, se encuentran los apodícticos, de los que Crisipo distingue cinco clases: 1) El constituido por una condición y una conclusión, comenzando con la condición para desprender de ella la conclusión: Si es de día, hay luz; ahora bien, es de día; por lo tanto, hay luz; 2) De la condición y de lo contrario de su conclusión se extrae una conclusión opuesta a la mayor: Si es de día, hay luz; ahora bien, es de noche, por lo tanto no es de día; 3) De premisas negativas y de uno de los términos de las premisas se concluye lo contrario del término restante: No es cierto que Platón esté vivo y muerto; ahora bien, Platón está muerto; por lo tanto, no está vivo; 4) De una disyunción y de uno de sus términos se concluye lo contrario del término restante: $O$ es de día o es de noche; ahora bien, es de día, por lo tanto no es de noche; 5) De una disyunción y del contrario de uno de

\footnotetext{
8. Las proposiciones, como recoge Brun en la obra citada, se clasifican así: 1- Proposición condicional, que depende de la conjunción condicional si y anuncia que una segunda proposición seguirá a la primera, ejemplo: Si es de día, hay luz; 2- la proposición consecutiva que depende de la conjunción puesto que, ejemplo: Puesto que es de día, hay luz; 3-la proposición coordinada que depende de la conjunción y: Es de día y hay luz; 4- La proposición disyuntiva, que introduce una disyunción mediante la disyuntiva $\mathrm{O}$ bien: $\mathrm{O}$ bien es de día o bien es de noche; 5 - La proposición causal que depende de la conjunción porque: Hay luz porque es de día; 6- La proposición comparativa: Es más noche que día, o Es menos noche que de día.
} 
sus términos se obtiene el término restante: $\mathrm{O}$ es de día o es de noche; ahora bien, no es de día, por lo tanto, no es de noche.

De la explicación anterior, podemos concluir que, en la manera de concebir los razonamientos, estos no dejan de reflejar una fuerte conexión con el mundo material (expresado en hechos, sucesos) más que una simple conexión entre conceptos, lo cual permite establecer que, en otras palabras, la lógica expresa leyes naturales, postura muy defendida por Crisipo, según puede inferirse de algunos de sus fragmentos (Crisipo, 2006, 36)

De esta breve exposición sobre la lógica podemos destacar varios aspectos importantes. Por una parte, la imbricación entre diferentes saberes dentro de la lógica, como la dialéctica y la teoría del conocimiento. Dicho nexo encuentra su justificación en que, para los estoicos, saber algo es ser capaz de demostrar que el argumento expuesto es válido, lo que es igual a decir que quien posee conocimiento puede probar por medio de proposiciones verdaderas aquello que sabe. De aquí se deriva una distinción entre lo verdadero (que es lo aplicable a la proposición) y la verdad (que es tomada en relación a una misma sustancia, la Naturaleza, la cadena de causas y efectos). Conocer la verdad es aprehender esta serie, ser capaz de conocer lo que ha de suceder, que está basado en el nexo causal que controla los eventos del Universo. Así las cosas:

"Un hombre es una criatura dotada naturalmente de la capacidad de ver conexiones (y de usar el lenguaje). Hacer esto es pensar articuladamente, hablar con uno mismo, ordenar las impresiones de la experiencia y crear nuevas ideas con ellas. Para los estoicos, el mundo todo es la obra de un logos o razón y, en su capacidad de pensamiento articulado, se le supone a un hombre en posesión de medios para formular afirmaciones que reflejen los acontecimientos cósmicos" (Long, 1997, 128).

Que la lógica y el conocimiento del mundo forman un mismo conjunto, y que ambas se necesitan entre sí, es la particularidad de la visión estoica. ¿Qué se debe conocer y expresar mediante la lógica? El mundo, el logos. La pregunta ahora es: ¿Para qué? El objetivo principal del estoicismo es el vivir bien, y vivir bien es vivir en armonía con el universo. Es, para explicarlo con otras palabras, el asentimiento con el todo, con el universo. Esto significa que el ideal estoico es vivir aceptando el logos que ordena, lo que no es otra cosa ue vivir de acuerdo con dios. El conocimiento permite realizar una armonía racional entre el hombre y el mundo, conocimiento que es demostrado y probado mediante proposiciones verdaderas. La lógica desempeña, por tanto, un papel importante para la consecución de este objetivo. De manera que física y lógica conducen a esta finalidad. No obstante, no todos los hombres pueden alcanzar tal objetivo. Un hombre común, consideran los estoicos, es capaz de dar ciertas afirmaciones sin ser capaz de probar su veracidad. Sólo el sabio está en capacidad de hacerlo. Más aún, el punto de vista estoico es demasiado rígido y considera que tales disciplinas (física y lógica) no pueden ser practicadas adecuadamente a menos que uno sea un hombre sabio, lo que es igual a decir que para ser un hombre sabio se requiere poseer alta competencia en física y lógica. Sin embargo, no es de importancia ahora discutir el punto de vista acerca del hombre sabio. Lo que nos interesa en este instante, ya como idea final de esta exposición, es poner de manifiesto la importancia de la lógica en la ética estoica, que, como ya se ha expuesto, consiste en vivir en armonía con la naturaleza, el logos, es decir, dios, y para esto es requisito indispensable conocerlo. La lógica abre el camino para reafirmar lo que aprendemos de la física: es la racionalización, verbalización, de ese logos presente en todo. De suerte que la lógica encuentra su sentido en la relación con la física y la ética. De la misma manera como todo en el qmundo se encuentra conectado, así también están estas disciplinas que forman la filosofía estoica. Bréhier expresa esta relación así:

"elles sont au contraire indissolublement liées, puisque c'est une seule et même raison, qui, dans la dialectique, enchaîne les propositions conséquentes aux antécédentes, dans la nature lie ensemble toutes les causes, et dans la conduite établit entre les actes le parfait accord. II est impossible que I'homme de bien ne soit pas le physicien et le dialecticien ; il est impossible de réaliser la rationalité séparément en ces trois domaines" (Bréhier, 1928, 208) ${ }^{8}$

En otras palabras, gracias al estudio de la lógica, el hombre puede lograr su objetivo de vivir en la felicidad. $Y$ ello, gracias a que la lógica le ayuda a comprender que el mundo es un entramado en el que ninguna cosa sucede aisladamente, de suerte que le facilita al hombre su desenvolvimiento en el mundo, pues mediante el uso de su razón (desarrollada por el estudio de la lógica), puede observar la causalidad operante en el mundo, y, por qué no, también proyectar sus actos, siempre pensando que dicha proyección obedece a lo que debería ser. ¿Por qué a lo que debería ser? Como se ha visto, dios, mundo,

\footnotetext{
8. "Por el contrario, están indisolublemente ligadas, pues es una sola y misma razón (ellogos) la que, en la dialéctica, encadena las proposiciones consiguientes con las antecedentes, la que en la naturaleza ensambla todas las causas y que en la conducta establece una armonía perfecta entre las acciones. Es imposible que el hombre bueno no sea físico ni dialéctico; es imposible que alcance la racionalidad separadamente en estos tres dominios" (La traducción es mía).
} 
naturaleza, cosmos, son varias formas de referirse a algo en concreto: la divinidad. De suerte que la lógica le permite al hombre entender a la divinidad, comprender los actos de ésta, y proyectar su actuación que, al ceñirse a la lógica, tratará de ser acorde con los designios de la divinidad. En últimas, se trata de vivir en simpatía con el universo, con dios: he ahí el ideal estoico. Y es este ideal el que dota de importancia a la lógica en la filosofía estoica, ya que sin aquella, el conocimiento de dios sería imposible, en tanto que el hombre no podría contemplar el mundo, las relaciones que lo componen, el orden que lo estructura. Sencillamente, no podría contemplar a dios, y mucho menos sentirse partícipe de él, de ese logos ordenador, y estaría sumergido en la infelicidad, pues sólo mediante el cultivo de la razón (a lo cual ayuda la lógica, así como las demás disciplinas) el hombre alcanza la felicidad: alcanza a dios.

\section{Referencias}

Bréhier, E. (1928). Histoire de la philosophie. — I. L'Antiquité et le Moyen âge. Paris: Librairie Félix Alcan

Brun, J. (1977). El estoicismo. Traducción de Thomas Moro Simpson. Buenos Aires: Editorial Universitaria de Buenos Aires.

Cicerón. (1999). Sobre la naturaleza de los dioses. Traducción de Ángel Escobar. Madrid: Gredos.

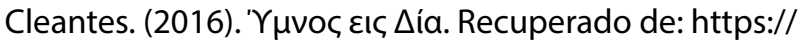

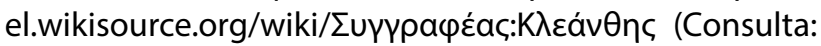
02.03.2015)

Crisipo de Solos. (2006). Testimonios y fragmentos I. Traducción de Javier Campos Daroca y Mariano Nava Contreras Madrid: Gredos.

Diógenes Laercio. (1990). Vidas de los filósofos más ilustres. Traducción de José Ortiz y Sanz. La Habana: Editorial de Ciencias Sociales.
Diógenes Laercio. (1990) Vidas de los filósofos más ilustres. Traducción de José Ortiz y Sanz. La Habana: Editorial de Ciencias Sociales.

Kneale, W. (1972). El desarrollo de la lógica. Traducción de Javier Muguerza. Madrid: Tecnos.

Long, A. (1996). Stoic studies. Cambridge: Cambridge University press.

Long, A. (1997). El estoicismo. En La filosofía helenística. Traducción de Jordán de Urries. Madrid. Alianza. Marco Aurelio. (1998). Soliloquios.Traducción de Antonio Brum y Jacinto Díaz de Miranda. México: Porrúa.

Mates, B. (1985). Lógica de los estoicos. Traducción de Miguel García Barós. Madrid: Tecnos.

Plutarco (1574). Varia Scripta. Recuperado en: https:// books.google.com.co/ books?id=EzJBAAAACAAJ \&print$\mathrm{sec}=$ frontcover $\mathrm{v}=$ onepage $\& \mathrm{q} \& \mathrm{f}=\mathrm{false} \quad$ (Consulta: 10.03.2015)

Rist, J. M. (1995). La filosofía estoica. Traducción de David Casacuberta. Barcelona: Crítica.

Sexto Empírico. (1997). Contra los profesores. Traducción de Jorge Bergua Cavero. Madrid: Gredos.

Vivieux-Reymond, A. (1945). La logique et l'épistemologie des stoïciens. Chambéry: Éditions Lire.

Voelke, A. (1973). L'idée de volonté dans le stoïcisme. Paris: Presses Universitaires de France. 